\title{
Expression of p53 isoforms in squamous cell carcinoma of the head and neck
}

\author{
Linda Boldrupa ${ }^{a,{ }^{*}}$, Jean-Christophe Bourdon ${ }^{b}$, Philip J. Coates ${ }^{c}$, Björn Sjöström $^{d}$, and Karin \\ Nylandera \\ aDepartment of Medical Biosciences/Pathology, Building 6M, 2nd floor, Umeå University, SE - \\ 90185 Umeå, Sweden \\ ${ }^{b}$ Department of Surgery and Molecular Oncology, University of Dundee, Ninewells Hospital and \\ Medical School, Dundee DD1 9SY, UK \\ 'Division of Pathology and Neurosciences, University of Dundee, Ninewells Hospital and Medical \\ School, Dundee DD1 9SY, UK \\ dDepartment of Clinical Sciences/Otorhinolaryngology, Umeå University Hospital, SE - 90187 \\ Umeå, Sweden
}

\begin{abstract}
Recent data indicate that, similar to p63 and p73, several different p53 isoforms can be produced in humans through alternative initiation of translation, usage of an internal promoter and alternative splicing. These isoforms are reported to have varying functions and expressions. In squamous cell carcinoma of the head and neck (SCCHN), disruption of the p53 pathway is one of the most common genetic alterations. However, to our knowledge, no studies regarding the expression of different p53 isoforms in SCCHN have so far been performed. We screened for the expression of different p53 isoforms in SCCHN and clinically normal oral epithelia using nested RT-PCR. p53 mRNA was expressed in all tumours, all matched clinically normal tissue adjacent to the tumour and in buccal mucosa from healthy volunteers. Of the novel isoforms, p $53 \beta$ was detected in the majority of samples analysed, and all of the recently described isoforms were also detected in at least some tumour and normal epithelium samples, with the exception of $\Delta \mathrm{p} 53$ isoforms. We conclude that p53 variant mRNAs are expressed in both normal oral stratified epithelium and SCCHN. Improvements in methodologies and reagents to detect and quantify p53 isoform expression in clinical material will be required to correlate p53 status with clinical outcomes.
\end{abstract}

\section{Keywords}

p53; p53ß; p63; Isoforms; SCCHN

\section{Introduction}

The tumour suppressor p53 was discovered in 1979 and 20 years later two relatives p631,2 and p733 were discovered, both with strong homologies to p53. By the use of different

\footnotetext{
() 2006 Elsevier Ltd. All rights reserved.

*Corresponding author: Tel.: +46 90785 2922; fax: +46 90785 2829. E-mail address: linda.boldrup@ @edbio.umu.se (L. Boldrup).. Conflict of interest statement

None declared.
} 
promoters and alternative splicing, the $p 63$ and $p 73$ genes give rise to six and 35 mRNAs, respectively. These mRNAs are translated into six p63 and theoretically 29 p73 protein isoforms.3-8 Although the TP53 gene has generally been thought of as producing only one protein, a variety of mRNA isoforms have been identified. In mouse, one form has been described, p53as.9-11 In humans many variants have now been reported: p53 $\beta$ (also called p53i9) caused by alternative splicing of intron $912-14$ and $\Delta 40 \mathrm{p} 53$ (also called p47 and $\Delta \mathrm{Np} 53)$ caused by alternative splicing of intron 215,16 or by altered initiation of translation. 17 Another $\mathrm{p} 53$ isoform recently described is $\Delta \mathrm{p} 53$, derived by alternative splicing and causing a lack of 65 internal amino acids. 18 By comparing the gene structure of p53 with p63 and p73, Bourdon and colleagues recently identified an additional promoter in intron 4 of the TP53 gene, giving rise to a novel isoform called $\Delta 133 \mathrm{p} 53$. They also showed alternative splicing of intron 9 , giving rise to $\beta$ - and $\gamma$-isoforms. 14 Combining these data indicates at least nine different $\mathrm{p} 53$ isoforms in humans: p53, p53 $\beta, \mathrm{p} 53 \gamma, \Delta 133 \mathrm{p} 53$, $\Delta 133 \mathrm{p} 53 \beta, \Delta 133 \mathrm{p} 53 \gamma, \Delta 40 \mathrm{p} 53, \Delta 40 \mathrm{p} 53 \beta$ and $\Delta 40 \mathrm{p} 53 \gamma$ (Fig. 1). 14

Data concerning the functional properties and expression of these isoforms are limited. $\Delta \mathrm{p} 53$ mRNA was found in primary and established primate cells of different tissue types and several human cell lines and was reported to be specifically involved in the ATR-intraS-phase checkpoint. 18 The $\Delta 40 \mathrm{p} 53$ protein has been demonstrated to alter the localisation of p53 within the cell and to inhibit mdm2-mediated degradation of p53.16 The expression patterns of p53 isoforms suggested that usage of the internal promoter in intron 4 and alternative splicing of intron 9 are regulated in a tissue dependent manner. In normal tissues, these isoforms appear to be expressed at different levels, with $\Delta 133 \mathrm{p} 53 \beta$ being the most tissue restricted.14 Importantly, when analysing breast carcinomas, none of the tumours had the same p53 isoform expression pattern as normal breast tissue. The isoforms expressed also varied between individual tumours, indicating potential roles for these p53 variants in human breast cancer.14

Squamous cell carcinoma of the head and neck ( $\mathrm{SCCHN}$ ) is the sixth most common cancer in the world and, like other human tumours, approximately 50\% show mutations in the TP53 gene. The prognostic significance of p53 mutation in SCCHN is reported to vary between different groups. 19 Such variability in significance of p53 mutation status is commonly seen in studies of human cancer and has been suggested to indicate the highly variable sensitivity and accuracy of the different methodologies employed.20 The potential for the production of different p53 isoforms with different characteristics may also represent an independent factor for the significance of p53 status in tumours. Therefore, we set out to analyse p53 isoforms in SCCHN at the mRNA and protein levels. Results showed that mRNAs coding for all of the newly described isoforms are expressed, with the exception of $\Delta p 53$, and p53 $\beta$ mRNA is the most commonly identified isoform.

\section{Materials and methods}

\subsection{Patients and specimens}

Biopsies of tumour were taken after informed consent from a limited number of 21 patients with primary SCCHN. Clinically normal tissue adjacent to the tumour was available from 16 of the patients. Punch biopsies ( $4 \mathrm{~mm}$ diameter) were also taken from the buccal mucosa of eight healthy non-smoking volunteers. Tissue samples were divided into two and immediately frozen in liquid nitrogen. Permission for the project had been granted by the Ethics Committee at Umeå University (dnr 01-057 and dnr 01-210). FaDu cells derived from a human SCCHN (ATCC) were maintained in DMEM with 10\% foetal calf serum (Invitrogen) at $37^{\circ} \mathrm{C}$. Exponentially growing cells were collected for RNA extraction and protein extraction. 


\subsection{RNA and protein extraction}

One half of the biopsy was used for RNA extraction as previously described.21 The extracted RNA was kept at $-80{ }^{\circ} \mathrm{C}$ until use. The other half of the biopsy from 14 tumours and the corresponding normal epithelial tissue and from the eight normal controls was used for protein extraction using a Microdismembrator (B. Braun. Biotech International) for pulverising the sample. One hundred $\mu \mathrm{l}$ of lysis buffer containing $0.5 \% \mathrm{NP}-40,0.5 \% \mathrm{Na}-$ doc, $0.1 \%$ SDS, $150 \mathrm{mM} \mathrm{NaCl}, 50 \mathrm{mM}$ Tris, $\mathrm{pH} 7.5,1 \mathrm{mM}$ EDTA, $1 \mathrm{mM} \mathrm{NaF}$ and protease inhibitor cocktail (Sigma-Aldrich Chemie, Steinheim, Germany) was added and the pulverised samples were homogenised. Protein concentrations were determined using BCA Protein Assay Kit (Pierce, Rockford, IL, USA).

\subsection{In vitro transcription translation (IVTT) of p53 proteins}

Vectors containing six of the different p53 isoforms were used for in vitro translation of proteins using the TNT Quick Coupled Transcription/Translation Systems (Promega, Madison, USA) according to the manufacturer's instructions.

\section{4. cDNA synthesis and RT-PCR}

cDNA was synthesised using a Cloned AMV First-Stand cDNA Synthesis kit (Invitrogen) according to the manufacturer's instructions and using $300 \mathrm{ng}$ of total RNA. cDNA was amplified in one round of PCR or two rounds of PCR (nested PCR). The following p53specific primer sets were used: for the first PCR of p53, p53 $\beta$ and p53 $\gamma$ : e2.1/RT1. For $\Delta 133 p 53, \Delta 133 p 53 \beta$ and $\Delta 133 p 53 \gamma:$ i4f1/ RT2 were used. For one round of PCR and for the second run in nested PCR primers for $\mathrm{p} 53$ were: e2/RT2; for $\mathrm{p} 53 \beta$ : e2/p53b; for $\mathrm{p} 53 \gamma$ : e2/p53g; for $\Delta 133 \mathrm{p} 53$ : i4f2/RDNp53; for $\Delta 133 \mathrm{p} 53 \beta$ : i4f2/p53b and for $\Delta 133 \mathrm{p} 53 \gamma$ : i4f2/ p53g.

Primer sequences:

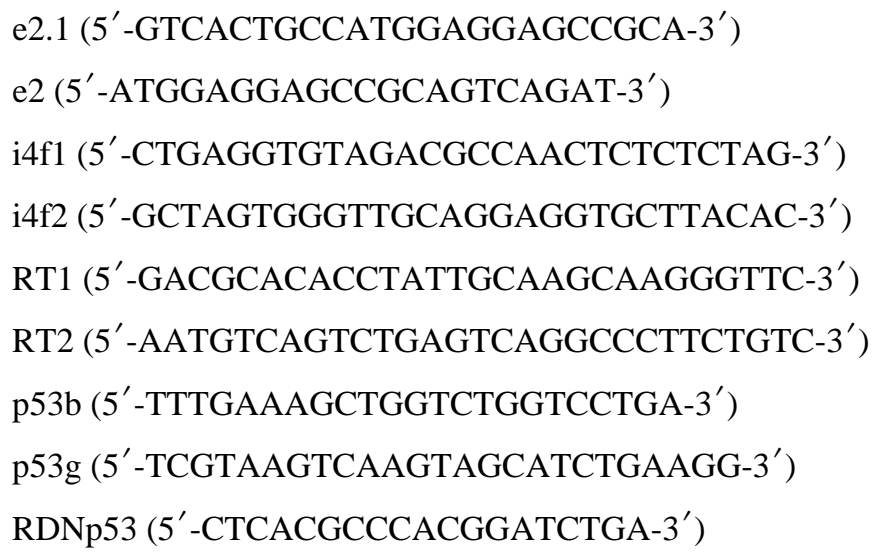

The PCR programme comprised 35 cycles with $94{ }^{\circ} \mathrm{C}$ for $30 \mathrm{~s}, 60^{\circ} \mathrm{C}$ for $45 \mathrm{~s}$ and $72{ }^{\circ} \mathrm{C}$ for $90 \mathrm{~s}$. PCR products were loaded on $1 \%$ agarose gels. All samples were analysed in duplicate.

\subsection{Immunoblot analysis and quantification}

Bio-Rad PROTEAN II xi | XL Vertical Electrophoresis system or vertical mini-gels were used according to the user manual. Thirty micrograms of protein was mixed with $2 \times$ loading buffer, boiled for $10 \mathrm{~min}$ and electrophoresed on 10\% SDS-polyacrylamide gels. The proteins were transferred to nitrocellulose membranes (Hybond ECL, Amersham Biosciences, Little Chalton, NA, USA) and stained with ponceau red for evaluation of 
transfer efficiency and loading. The membranes were blocked in 5\% milk with $0.4 \%$ Tween in $1 \times$ PBS, and antibodies diluted in the same blocking solution. Primary antibodies used in this study were DO-1,22 DO-12,23 1801 (Abcam, Cambridge, UK) and a polyclonal antip53 (Sapu). Secondary antibodies used were peroxidase-labelled rabbit anti-mouse, rabbit anti-sheep and goat anti-rabbit (DakoCytometric, Glostrup, Denmark). For chemiluminescence detection, Chemidoc XRS (Bio-Rad) was used in combination with ECL advance (Amersham Biosciences, Little Chalton, NA, USA) for development.

\section{Results}

\subsection{Expression of p53 isoforms by RT-PCR}

By using specific primers and nested RT/PCR, six different $\mathrm{p} 53$ isoforms could be specifically amplified: $p 53, p 53 \beta, p 53 \gamma, \Delta 133 \mathrm{p} 53, \Delta 133 \mathrm{p} 53 \beta$ and $\Delta 133 \mathrm{p} 53 \gamma$. p53 mRNA was consistently detected in replicate analyses of all 21 tumour samples (T), all 16 clinically normal tissues adjacent to the tumour $(\mathrm{N})$ and all 8 samples of buccal mucosa from nonsmoking healthy volunteers (NS). In analysis of p53 $\beta$ mRNA, one tumour sample, two nontumour adjacent samples and two samples from healthy volunteers showed inconsistent results, where in replicate assays samples were either positive or negative. From the remaining 40 samples, 18/20 tumour samples, 13/14 normal tissue adjacent to the tumour and 6/6 normal control samples (NS) showed positive amplification of p53 $\beta$ (Fig. 2). Thus, p53 $\beta$ was consistently amplified in 37 out of 40 samples (92.5\%). Nested PCR consistently indicated the presence of $533 \gamma(5 \mathrm{~T} / 3 \mathrm{~N} / 6 \mathrm{NS}), \Delta 133 \mathrm{p} 53$ (7T/9N/3NS), $\Delta 133 \mathrm{p} 53 \beta(3 \mathrm{~T} / 2 \mathrm{~N} /$ $0 \mathrm{NS})$ and $\Delta 133 \mathrm{p} 53 \gamma(4 \mathrm{~T} / 1 \mathrm{~N} / 2 \mathrm{NS})$ isoforms. The $\Delta \mathrm{p} 53$ isoform identified as a variant lacking 198 nucleotides from exons 7-918 was not detected in any sample (Fig. 3a). We also examined p53 isoform mRNAs in the human SCCHN cell line, FaDu. Positive amplification was obtained for each of the p53 isoform mRNAs, with the exception of the $\Delta$ p53 variants.

Analysing the samples with only one round of PCR using the inner primer pair showed positive results in 34 samples for $\mathrm{p} 53$, in 22 samples for $\mathrm{p} 53 \beta$, and in two samples for $\Delta 133$ p53. p53 $\gamma, \Delta 133$ p53 $\beta$ and $\Delta 133$ p53 $\gamma$ were not detectable with only one PCR (Fig. $3 b)$.

\subsection{Immunoblot analysis}

In order to evaluate different antibodies in recognition of the different $\mathrm{p} 53$ isoforms, in vitro translated proteins were produced and different antibodies tested (Fig. 4). The DO-12 antibody directed against an epitope within the DNA-binding domain of p53, amino acids 256-27023 does not recognise $\Delta \mathrm{p} 53$, lacking these amino acids.18 The antibody, however, recognises the $\mathrm{p} 53, \mathrm{p} 53 \beta, \mathrm{p} 53 \gamma, \Delta 133 \mathrm{p} 53, \Delta 133 \mathrm{p} 53 \beta, \Delta 133 \mathrm{p} 53 \gamma, \Delta 40 \mathrm{p} 53, \Delta 40 \mathrm{p} 53 \beta$, and $\Delta 40 \mathrm{p} 53 \gamma$ isoforms. Fig. $4 \mathrm{a}$ demonstrates the ability of DO-12 to recognise each of these isoforms, and also gives their approximate sizes. The DO- 1 antibody recognises an epitope located at amino acids 20-25, and therefore does not recognise the $\mathrm{N}$-terminal truncated $\Delta 133$ p53 or $\Delta 40$ p53 isoforms. The monoclonal antibody 1801 recognises an epitope located within residues $32-79$ and recognises $\Delta 40 \mathrm{p} 53$ isoforms but not $\Delta 133 \mathrm{p} 53$ proteins. The polyclonal serum Sapu recognises all isoforms, although with variable intensity. To investigate if the control cell line used in RT-PCR as positive control also expressed the novel p53 isoforms at protein levels, the different antibodies were tested along-side the in vitro translated isoforms. The results showed that the only isoform detectable in $\mathrm{FaDu}$ was p53 (Fig. 4).

When the tumours and clinically normal tumour adjacent tissues were analysed with DO-1, we noted variability in the apparent molecular weight of p53 in different samples. For instance, the mobility of the $\mathrm{p} 53$ band in T/N1 was higher than that seen in HeLa cell lysate, 
whilst in T/N10 and T/N14 a double band was observed (Fig. 5). In five pairs, p53 levels were too low for detection, while in two pairs normal tissue adjacent to the tumour had higher levels than the tumour. In normal control tissues, however, p53 could not be detected with DO-1 at the concentration used and the detection system employed (results not shown). The same samples were analysed with DO-12, which gave similar results and did not identify band $\mathrm{s}$ at the sizes of the $\mathrm{N}$-terminally truncated $\Delta 40 \mathrm{p} 53$ or $\Delta 133 \mathrm{p} 53$ proteins.

In these immunoblots, $\beta$-actin was used as an internal control for variations in protein loading. According to $\beta$-actin, variable amounts of protein had been loaded, although staining with both ponceau and coomassie showed a low variance between samples, indicating that there is a difference in $\beta$-actin content in both normal and tumour tissues as well as an inter-individual variance. 24

\section{Discussion}

Previous studies of p53 in squamous cell carcinoma of the head and neck (SCCHN) have not defined any clear prognostic impact to this factor. In addition to problems with different methods and sensitivity of mutation detection, the recent findings of multiple isoforms encoded by the TP53 gene may provide an additional factor complicating the analysis of p53 in human tumours, as the p53 so extensively studied is just one of the many different isoforms that may be present in human cells.14 In the present study, we mapped the expression of the newly described p53 isoforms in SCCHN at mRNA level. Using the twostage nested RT-PCR protocol described previously, 14 we could specifically amplify all of the novel p53 isoforms in at least one of each sample type analysed (tumour, normal tissue adjacent to the tumour and normal control mucosa) with the exception of $\Delta \mathrm{p} 53$, which was not detected in any of the primary SCCHN tumours or normal tissue samples, or in cultured SCCHN cells. It should be noted that the nested PCR method employed here and elsewhere can identify extremely low levels of mRNA. In our hands, p53 was always amplified robustly and consistently in all samples and similar results were seen for $\mathrm{p} 53 \beta$, although not all samples were positive and some inconsistencies were observed using different cDNA preparations from the same samples. For the other isoforms, amplified products were less intense at analysis on agarose gels and amplification commonly gave inconsistent results. A limiting factor in our studies was the amount of input cDNA that could be used from the material available in tumour biopsies and the large number of PCRs required for each sample, and it would be expected that results would be less variable if more tissue sample could have been used. Nonetheless, these data are compatible with comparatively low level expression of p53 isoform mRNAs compared to p53 itself. The data from only one round PCR instead of nested PCR support this theory. These results are not surprising, given the number of workers that have investigated p53 in the past and the paucity of reports that have detected p53 variants in those studies.

Our data indicate the expression of numerous p53 mRNA isoforms in normal and neoplastic stratified oral epithelia. Even if present at low levels, p53 protein is regulated predominantly by post-translational mechanisms and does not correlate with mRNA levels.25 Therefore, we also analysed p53 isoform expression by immunoblotting. One of the most frequently used antibodies for the detection of p53, DO-1, also detects the p $53 \beta$ and $\mathrm{p} 53 \gamma$ proteins, but does not recognise $\Delta 40 \mathrm{p} 53$ or $\Delta 133 \mathrm{p} 53$ isoforms. The p53 $\beta$ and $\mathrm{p} 53 \gamma$ isoforms differ very little in apparent size compared to p53 and detection of these isoforms could thus previously have been missed if mixtures of the three proteins of overlapping size were present in the same sample, particularly if the filter was over-loaded and/or over-developed (often seen in tumours with large amounts of stabilised mutant protein). Alternatively, faster migrating bands may often be dismissed and taken as an indication of protein degradation. In our samples, different mobility proteins were identified using well-characterised p53 
monoclonal antibodies that recognise distinct epitopes and differentially identify the different isoforms. However, we were unable to demonstrate the presence of bands at the predicted sizes of p53 isoforms by direct western blotting of primary tumour material or FaDu cells. These observations do not exclude the presence of these proteins, which may be present at low levels, but indicate that analysis of p53 isoform proteins will require the generation of mono-specific reagents to identify and distinguish individual protein isoforms.

In conclusion, we show that novel p53 mRNAs are expressed in SCCHN and the corresponding normal tissues, with the exception of $\Delta \mathrm{p} 53$. Although our data suggest that novel p53 variants represent a minority of total cellular p53, a role for these isoforms cannot be discounted in view of their potential for interaction with p53 and other p53-family members to alter the balance of p53, p63 and p73 transcriptional activities during normal and neoplastic cell growth. 8 From the present results, we can conclude that out of the recently detected p53 isoforms, p53 $\beta$ is the most easily identified isoform in SCCHN and the other isoforms are more difficult to identify. Our work also highlights that the issues of tissue collection and storage, the quality of mRNA and protein preparations and the sensitivities of isoform-specific PCR primers (with limited options for optimal primer design) will need to be addressed and standardised to provide optimal conditions for future studies of the role of p53 isoform expression in human diseases. In view of the demonstrated abilities of low levels of p53 $\beta$ isoforms to induce preferential binding of p53 to target genes such as bax versus p21,8,14 we hypothesise that promoter specificity for the 2000 or so potential p53 target genes is determined at least in part by the combinations of p53 isoforms expressed in individual tumours. Following our demonstrations of differential isoform expression in individual squamous tumours, further studies will be needed to determine the impact of their expression on p53 activities and the relationships between different isoform expression patterns and clinical outcome.

\section{Acknowledgments}

We are grateful for the skilful help of Bodil Bäcklund. This study was supported by grants from the Cancer research Foundation in Northern Sweden, Lion's Cancer Research Foundation, Umeå University, Kvinnliga Tandläkarklubben, and the Swedish Cancer Society Grant number 4569-B05-05XAC. P.J. Coates is supported by the Association for International Cancer Research.

\section{REFERENCES}

1. Yang A, Kaghad M, Wang Y, et al. p63, a p53 homolog at 3q27-29, encodes multiple products with transactivating, death-inducing, and dominant-negative activities. Mol Cell. 1998; 2:305-16. [PubMed: 9774969]

2. Osada M, Ohba M, Kawahara C, et al. Cloning and functional analysis of human $\mathrm{p} 51$, which structurally and functionally resembles p53. Nat Med. 1998; 4:839-43. [PubMed: 9662378]

3. Kaghad M, Bonnet H, Yang A, et al. Monoallelically expressed gene related to $\mathrm{p} 53$ at 1p36, a region frequently deleted in neuroblastoma and other human cancers. Cell. 1997; 90:809-19. [PubMed: 9288759]

4. De Laurenzi V, Costanzo A, Barcaroli D, et al. Two new p73 splice variants, gamma and delta, with different transcriptional activity. J Exp Med. 1998; 188:1763-8. [PubMed: 9802988]

5. Fillippovich I, Sorokina N, Gatei M, et al. Transactivation-deficient p73alpha (p73Deltaexon2) inhibits apoptosis and competes with p53. Oncogene. 2001; 20:514-22. [PubMed: 11313982]

6. Yang A, Walker N, Bronson R, et al. p73-deficient mice have neurological, pheromonal and inflammatory defects but lack spontaneous tumours. Nature. 2000; 404:99-103. [PubMed: 10716451]

7. Pozniak CD, Radinovic S, Yang A, et al. An anti-apoptotic role for the p53 family member, p73, during developmental neuron death. Science. 2000; 289:304-6. [PubMed: 10894779] 
8. Murray-Zmijewski F, Lane DP, Bourdon JC. p53/p63/p73 isoforms: an orchestra of isoforms to harmonise cell differentiation and response to stress. Cell Death Differ. 2006

9. Wolf D, Harris N, Goldfinger N, Rotter V. Isolation of a full-length mouse cDNA clone coding for an immunologically distinct p53 molecule. Mol Cell Biol. 1985; 5:127-32. [PubMed: 2580227]

10. Arai N, Nomura D, Yokota K, et al. Immunologically distinct p53 molecules generated by alternative splicing. Mol Cell Biol. 1986; 6:3232-9. [PubMed: 3023970]

11. Han KA, Kulesz-Martin MF. Alternatively spliced p53 RNA in transformed and normal cells of different tissue types. Nucleic Acids Res. 1992; 20:1979-81. [PubMed: 1579500]

12. Flaman JM, Waridel F, Estreicher A, et al. The human tumour suppressor gene p53 is alternatively spliced in normal cells. Oncogene. 1996; 12:813-8. [PubMed: 8632903]

13. Chow VT, Quek HH, Tock EP. Alternative splicing of the p53 tumor suppressor gene in the Molt-4 T-lymphoblastic leukemia cell line. Cancer Lett. 1993; 73:141-8. [PubMed: 8221626]

14. Bourdon JC, Fernandes K, Murray-Zmijewski F, et al. p53 isoforms can regulate p53 transcriptional activity. Genes Dev. 2005; 19:2122-37. [PubMed: 16131611]

15. Courtois S, Verhaegh G, North S, et al. DeltaN-p53, a natural isoform of p53 lacking the first transactivation domain, counteracts growth suppression by wild-type p53. Oncogene. 2002; 21:6722-8. [PubMed: 12360399]

16. Ghosh A, Stewart D, Matlashewski G. Regulation of human p53 activity and cell localization by alternative splicing. Mol Cell Biol. 2004; 24:7987-97. [PubMed: 15340061]

17. Yin Y, Stephen CW, Luciani MG, Fahraeus R. p53 Stability and activity is regulated by Mdm2mediated induction of alternative p53 translation products. Nat Cell Biol. 2002; 4:462-7. [PubMed: 12032546]

18. Rohaly G, Chemnitz J, Dehde S, et al. A novel human p53 isoform is an essential element of the ATR-intra-S phase checkpoint. Cell. 2005; 122:21-32. [PubMed: 16009130]

19. Nylander K, Dabelsteen E, Hall PA. The p53 molecule and its prognostic role in squamous cell carcinomas of the head and neck. J Oral Pathol Med. 2000; 29:413-25. [PubMed: 11016683]

20. Munro AJ, Lain S, Lane DP. P53 abnormalities and outcomes in colorectal cancer: a systematic review. Br J Cancer. 2005; 92:434-44. [PubMed: 15668707]

21. Thurfjell N, Coates PJ, Uusitalo T, et al. Complex p63 mRNA isoform expression patterns in squamous cell carcinoma of the head and neck. Int J Oncol. 2004; 25:27-35. [PubMed: 15201986]

22. Stephen CW, Helminen P, Lane DP. Characterisation of epitopes on human p53 using phagedisplayed peptide libraries: insights into antibody-peptide interactions. J Mol Biol. 1995; 248:5878. [PubMed: 7537340]

23. Vojtesek B, Dolezalova H, Lauerova L, et al. Conformational changes in p53 analysed using new antibodies to the core DNA binding domain of the protein. Oncogene. 1995; 10:389-93. [PubMed: 7530828]

24. Boldrup L, Coates PJ, Hedberg Y, et al. Expression of p63, COX-2, EGFR and beta-catenin in smokers and patients with squamous cell carcinoma of the head and neck reveal variations in nonneoplastic tissue and no obvious changes in smokers. Int J Oncol. 2005; 27:1661-7. [PubMed: 16273222]

25. Prives C, Hall PA. The p53 pathway. J Pathol. 1999; 187:112-26. [PubMed: 10341712] 


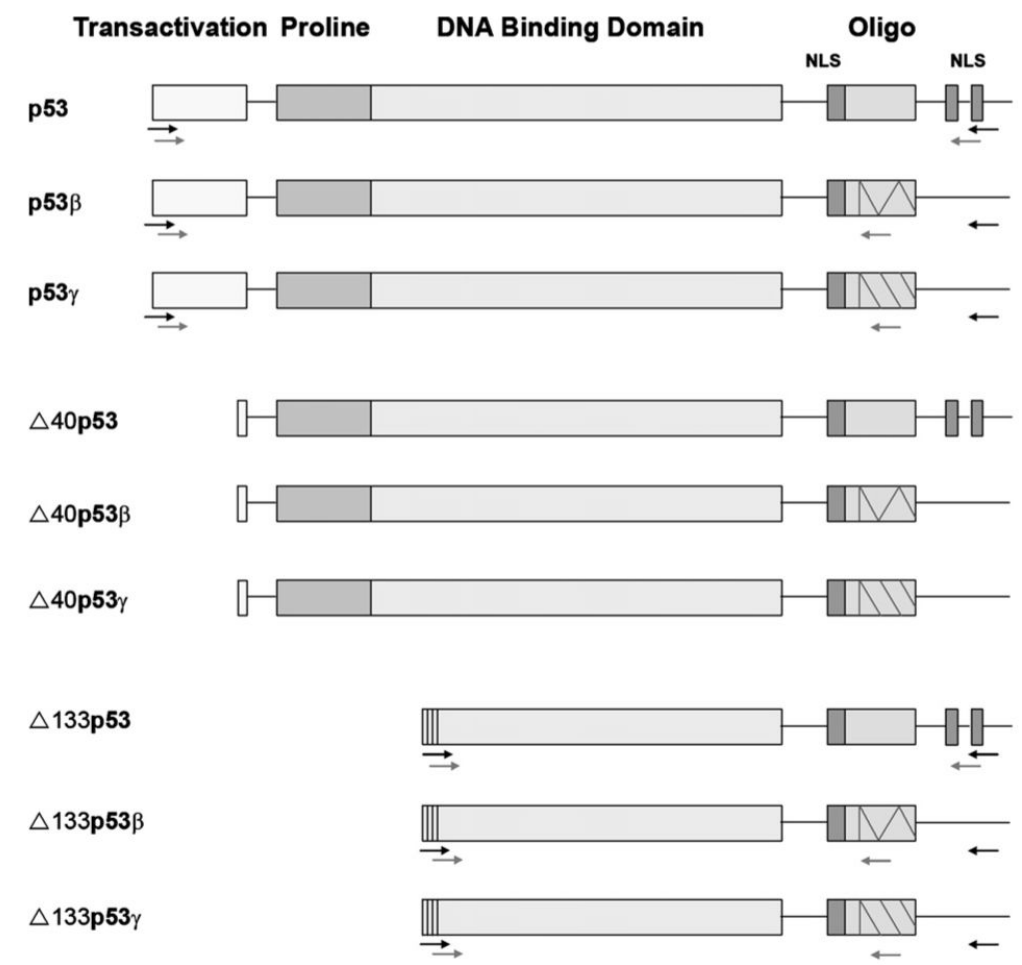

Fig. 1.

Structure of theoretically encoded p53 proteins. For detection of RNA of the different p53 isoforms, nested PCR was used. The primers used in the first round of PCR are illustrated with black arrows and the primers used for the second round of PCR are illustrated with grey arrows. 


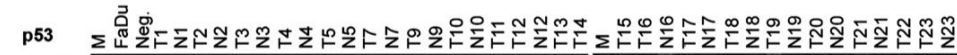
$1500 \mathrm{~kb} 0-000000000000000000$ (1)

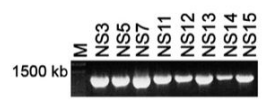

b

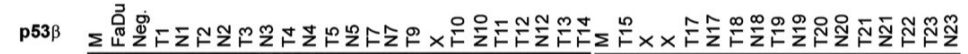

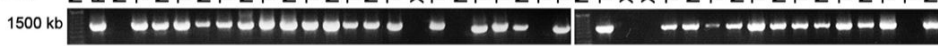

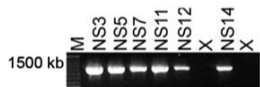

C

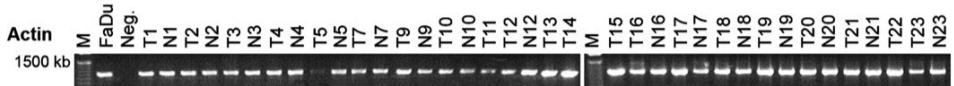

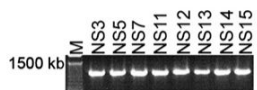

Fig. 2.

Expression of p53 isoforms in tumour tissue (T), clinically normal tumour adjacent tissue (N) in patients with squamous cell carcinoma of the head and neck, and healthy nonsmoking controls (NS) detected by nested RT-PCR. (a) Detection of p53, size of the amplified fragment was $-1250 \mathrm{bp}$. (b) Detection of $\mathrm{p} 53 \beta$, size of the fragment was - 1050 bp. (c) Actin is shown as control. $\mathrm{X}$ indicates samples showing variable results in duplicate analysis that could not be classified as either positive or negative. $\mathrm{M}$ indicates molecular weight marker. p53, p53 $\beta$ and actin are amplified from the same cDNA samples, T5 has lower actin in this run but in the duplicate all samples have the same actin level. 

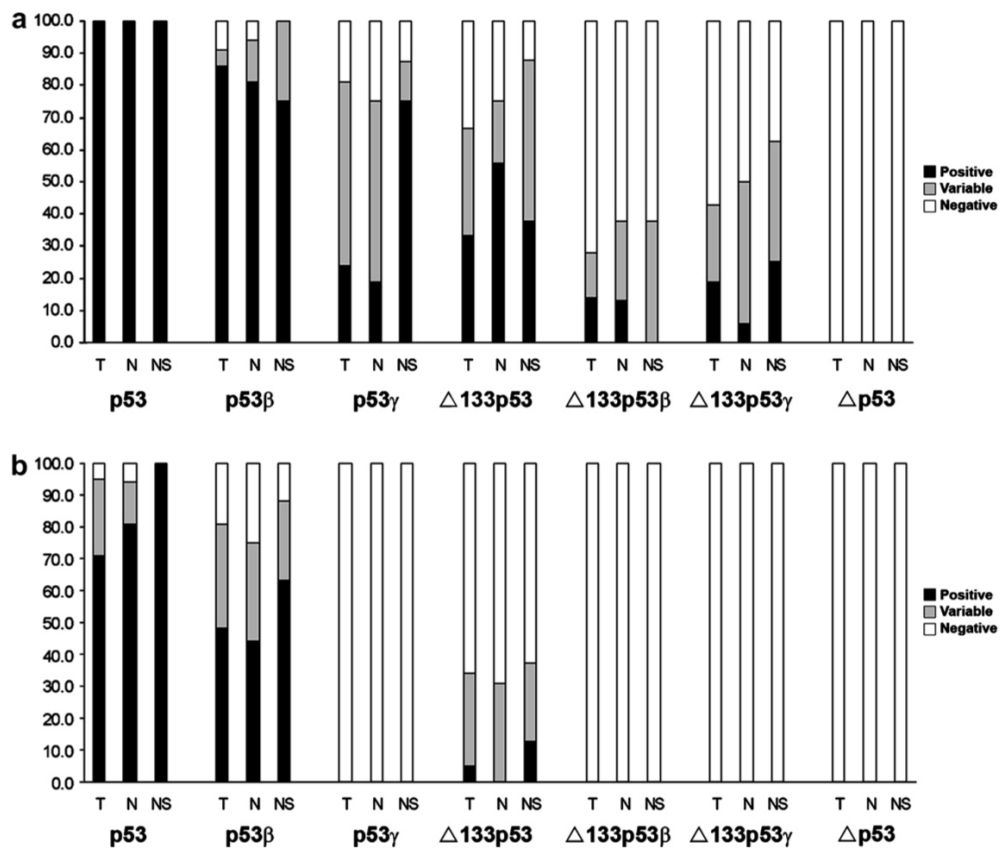

Fig. 3.

Summary of RT-PCR results. Bars show percent of positive (black bars) and negative (white bars) samples. In total 45 samples were analysed, 21 tumours (T), 16 clinically normal tumour adjacent tissue (N) and eight normal control samples (non-smokers) (NS). (a) Results from nested RT-PCR. (b) Results from PCR using only the inner primer pair. 
a

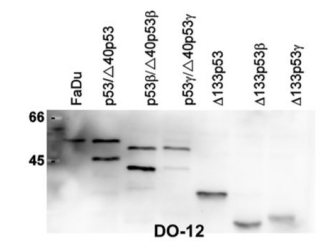

b

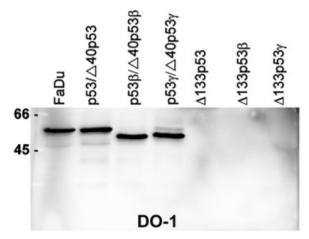

c

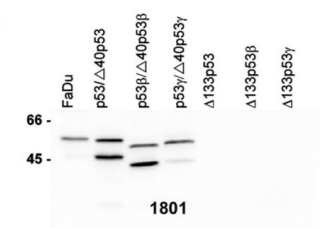

d

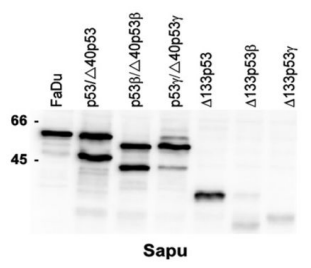

Fig. 4.

Detection of in vitro translated p53 isoforms and p53 protein in FaDu cell line expressing p53. (a) DO-12 antibody recognising all nine isoforms, p53, p53 $\beta, \mathrm{p} 53 \gamma, \Delta 40 \mathrm{p} 53$ (lower band in lane p53), $\Delta 40 \mathrm{p} 53 \beta$ (lower band in lane p53 $\beta$ ), $\Delta 40 \mathrm{p} 53 \gamma$ (lower band in lane $\mathrm{p} 53 \gamma), \Delta 133 \mathrm{p} 53, \Delta 133 \mathrm{p} 53 \beta$ and $\Delta 133 \mathrm{p} 53 \gamma$. (b) DO- 1 antibody, recognising $\mathrm{p} 53, \mathrm{p} 53 \beta$ and p53 $\gamma$. (c) 1801 antibody recognises p53 and $\Delta 40$ p53 isoforms. (d) Polyclonal Sapu serum recognising all p53 isoforms, although with different sensitivities. 


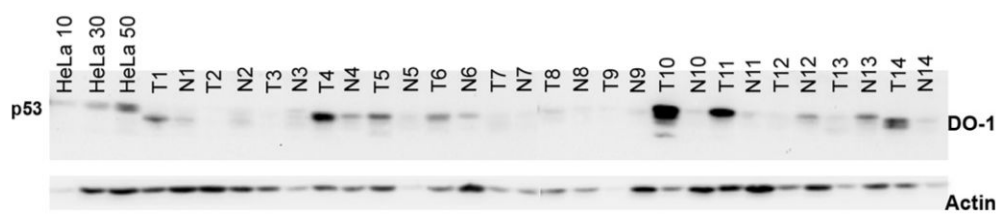

Fig. 5.

Western blot of 14 pairs of tumours $(\mathrm{T})$ and clinically normal tumour adjacent tissue $(\mathrm{N})$ from patients with squamous cell carcinoma of the head and neck. Detection of p53 using the DO-1 antibody. First three lanes show HeLa cell extract at different concentrations (10, 30 and $50 \mu \mathrm{g} / \mu \mathrm{l}$ ) as control. The following lanes show the 14 pairs of tumours and clinically normal tumour adjacent tissue. 